\title{
Charges e a história cultural da ciência: o eclipse e a deflexão da luz
}

\author{
Vinicius Jacques*, Lucas Albuquerque do Nascimento* ${ }^{\star \star}$ Henrique César da Silva ${ }^{\star \star \star}$
}

\section{Resumo}

Este artigo teve como objetivo analisar os aspectos históricos e textuais de charges que possuem relações com as tentativas de observação de eclipses referentes à deflexão da luz, realizadas no Brasil em 1912 e 1919, por meio da História Cultural da Ciência articulada com a noção de textualização. Assim, procuramos não analisar separadamente o texto (charge) dos conhecimentos e práticas relacionados aos episódios históricos. As charges analisadas foram publicadas em O Malho, uma revista ilustrada de grande circulação e repercussão na década de 1910. A seleção das charges se deu a partir de buscas na Biblioteca Nacional Digital. A análise das charges evidenciou processos de representação de uma prática científica comumente invisibilizada, a tentativa de observação do eclipse total do Sol em 1912; favoreceu a visibilidade de ações produzidas por outros atores, como Henrique Morize e Charles Dillon Perrine; destacou práticas científicas como as interações entre Perrine e Eddington; a busca por financiamento e atrasos na liberação de recursos e fatores que foram determinantes para a escolha dos pontos de observação, como a proximidade destes às ferrovias. Os elementos apresentados sinalizam potencialidades da utilização de charges no ensino de Física, numa perspectiva da História Cultural da Ciência articulada à textualização, onde a charge é a divulgação e elemento cultural constitutivo de uma prática científica. A análise sinaliza a relação entre texto/linguagem, suas práticas social, cultural e política de produção, com a dimensão conceitual, coletiva, histórica e epistemológica da produção da ciência.

Palavras-chaves: História Cultural da Ciência; Textualização; Charges; Deflexão da Luz; Eclipse.

Instituto Federal de Santa Catarina/Doutorando pelo Programa de Pós-Graduação em Educação Cientíica e Tecnológica da Universidade Federal de Santa Catarina - PPGECT/UFSC. Membro do Grupo de Pesquisa FLUXO - Circulação e Textualização da Ciência e Educação Científica. E-mail: vinicius.jacques@ifsc.edu.br

* Doutorando pelo Programa de Pós-Graduação em Educação Científica e Tecnológica da Universidade Federal de Santa Catarina - PPGECT/UFSC. Membro do Grupo de Pesquisa FLUXO - Circulação e Textualização da Ciência e Educação Científica. E-mail: lucas.albuquerque13@hotmail.com

** Universidade Federal de Santa Catarina/Centro de Ciências da Educação/Departamento de Metodologia de Ensino/Programa de Pós-Graduação em Educação Científica e Tecnológica - PPGECT/UFSC. Líder do Grupo de Pesquisa FLUXO - Circulação e Textualização da Ciência e Educação Científica (https://fluxo.ufsc.br/). E-mail: henriquecsilva@gmail.com

https://doi.org/10.5335/rbecm.v4i3.12910

http://creativecommons.org/licenses/by-nc-nd/4.0

ISSN: 2595-7376 


\section{Introdução}

Este artigo teve como objetivo analisar os aspectos históricos e textuais de charges que possuem relações com as tentativas de observação de eclipses referentes à deflexão da luz, realizadas no Brasil em 1912 e 1919, e com a corroboração empírica da Teoria da Relatividade Geral (TRG), numa perspectiva historiográfica da História Cultural da Ciência (HCC) (PIMENTEL, 2010) articulada com a noção de textualização (SILVA, 2019).

A análise de charges que propomos e realizamos neste artigo pode contribuir com subsídios para incorporá-las em episódios de ensino sobre a história da TRG, particularmente, episódios que abordam as tentativas de medidas da deflexão da luz de estrelas durante eclipses total do sol, como os casos que passam pela história e culturas brasileiras, a saber: o eclipse de 1912 em Passa Quatro - Minas Gerais e o de 1919 em Sobral - Ceará.

A HCC, desenvolvida em trabalhos como os de Moura e Guerra (2016), Peron e Guerra (2017), Moura et al. (2017), Camel et al. (2019) e Abalada e Guerra (2020), tornou-se uma abordagem importante para a Educação em Ciências. Esta perspectiva historiográfica ressalta o papel do contexto sociocultural na construção das Ciências, tem seu foco deslocado dos estudos das grandes ideias e cientistas, para ações de diferentes atores e dedica atenção às práticas científicas e às formas de representação do conhecimento científico desenvolvidas em determinado contexto (MOURA; GUERRA, 2016). Nesse sentido, práticas e representações que refiguram o conhecimento científico e incluem "relações com a cultura mais ampla, através da atuação de não cientistas na ciência, da divulgação desse conhecimento ao público amplo, das relações socioinstitucionais que ali se desenvolvem e da própria explicitação dos contextos históricos mais gerais nos quais estas práticas científicas se desenvolveram" (MOURA; GUERRA, 2016, p. 740-741).

Como os autores que têm trabalhado essa abordagem, acreditamos que este aporte historiográfico pode dar suporte a intervenções pedagógicas no ensino em, sobre e pelas Ciências (SANTOS, 1999) para a tomada de decisões em temáticas de interesse público. E para isso, um dos pontos de partida é o conhecimento da herança cultural - um conhecimento social e político, para além do conhecimento conceitual e epistemológico (MOURA; GUERRA, 2016). 
Nessa perspectiva historiográfica, o foco não ocorre apenas nos mecanismos de produção dos objetos culturais, mas também nos mecanismos de recepção (BURKE, 2008). Nessa direção, Secord (2004) aponta a Ciência como uma atividade de comunicação e circulação. $\mathrm{O}$ autor indica, ainda, que a compreensão do conhecimento científico como prática superou as "fronteiras entre 'interno' e 'externo' e abriu uma visão da ciência como um processo, incluindo investigações sobre experimentos, trabalho de campo e elaboração de teorias. Mais fundamentalmente, quebrou velhas distinções entre palavras e coisas, entre textos, livros, instrumentos e imagens" (SECORD, 2004, p. 658, tradução nossa).

Assim como Secord (2004), entendemos as Ciências como formas de comunicação. Daí a necessidade de dar atenção às práticas de circulação - que se dão de diferentes formas e podem reunir uma variedade de abordagens. Diante desse cenário "se a ciência é realmente uma atividade exercida por pessoas, o estudo das práticas comunicativas deveria ser algo que todos nós fazemos o tempo todo" (SECORD, 2004, p. 670, tradução nossa).

A circulação do conhecimento se dá em diferentes modos textuais (SILVA, 2019). Na vertente da HCC os textos são artefatos culturais que fazem parte da produção, textualização e circulação dos conhecimentos. Consideramos que os textos têm valor e materialidade, são constitutivos e não secundários, ou seja, os textos não são apenas veículos neutros de algo que circula e de um conteúdo que comunicam, os textos são peças materiais desses processos.

Para a HCC, os artefatos textuais considerados vêm sendo ampliados para além dos textos verbais. Pimentel (2010, p. 421, tradução nossa) aponta que: "Os estudos visuais têm penetrado fortemente na historiografia e em termos gerais podemos dizer que os historiadores hoje deixaram de considerar as imagens como ilustrações, para tratá-las como fontes, passíveis de serem interrogadas, lidas e interpretadas como se fossem um texto". Na mesma direção, Secord (2004, p. 665, tradução nossa) salienta que: "Todas as evidências do passado estão na forma de coisas materiais. Este é (ou melhor, tornou-se) óbvio no caso de instrumentos experimentais, espécimes de história natural, e modelos tridimensionais. Mas é igualmente verdadeiro para panfletos, desenhos, jornais, artigos, cadernos, diagramas, pinturas e gravuras". $\mathrm{E}$, questionamos neste artigo, por que não charges?

As charges, um dos gêneros dos quadrinhos (RAMOS, 2010), são uma das formas de circulação do conhecimento científico. As charges, comumente utilizadas em sátira 
política desde sua origem, ampliaram seu contexto de satirização, articulando-se a eventos científicos e circulando em diferentes meios.

As charges publicadas no contexto das tentativas de observação de eclipses referentes à deflexão da luz, em 1912 e 1919, objetos de estudo deste artigo, circularam em revistas ilustradas da época no Brasil. Revistas que eram veículos de comunicação de massa e que tinham em $O$ Malho "a mais interessante Revista Ilustrada da República Velha, não só por sua permanente intervenção humorística na política do país, como também pela qualidade dos chargistas que reuniu durante sua longa existência" (TEIXEIRA, 2001, p. 33).

Para Teixeira (2001, p. 33), O Malho era uma revista com "consistência política e importância cultural", que ao produzir e publicar charges elege a política "para a expressão de sua forma e manifestação de seu conteúdo" (ibidem, p. 05). "Em consequência, a eficácia de seu discurso está organicamente ligada à sociedade na qual se insere" (ibidem, p. 05). Assim, acreditamos que a análise das charges, relacionadas às tentativas de observação de eclipses, podem oferecer subsídios que favoreçam um conhecimento social e político, para além do conhecimento conceitual (MOURA; GUERRA, 2016; MOURA, 2019), sinalizando uma relação que por vezes não é tão simples.

Não concebemos as charges como subcultura, numa conotação depreciativa, mas como artefatos da "cultura de massa", e, peças de uma prática de circulação, dos modos de recepção da ciência pelo público. Barros (2003, p. 145) aponta que "qualquer objeto material produzido pelo homem faz também parte da cultura - da cultura material”. Salienta, ainda, que a vida cotidiana está imersa no mundo da cultura. "A própria linguagem, e as práticas discursivas que constituem a substância da vida social, embasam esta noção mais ampla de Cultura. 'Comunicar' é produzir Cultura [...]" (BARROS, 2003, p. 146).

Se, por um lado, a perspectiva da HCC permite pensar o papel de artefatos culturais na produção histórica da ciência, por outro lado, se estamos pensando nas potencialidades dessa perspectiva historiográfica para a educação em ciências, é importante lembrar que os quadrinhos são um produto de cultura de massa de grande penetração popular e aceitação entre os estudantes (VERGUEIRO, 2018). Vergueiro (2018) salienta que mesmo com o surgimento de outros meios de comunicação e entretenimento, cada vez mais diversificados e sofisticados, os quadrinhos 
continuam sendo atrativos e estão presentes em todos os países. Os quadrinhos têm se adentrado nas escolas e por consequência nas salas de aula.

Neste contexto, diversos autores (ASSIS; MARINHO, 2016; FIORAVANTI et al., 2016; VERGUEIRO, 2018; JACQUES, 2019) têm destacado as vantagens da utilização dos quadrinhos no ensino, uma vez que possuem uma relação semiótica do icônico e do verbal - uma linguagem que favorece a compreensão e identificação do leitor com o enredo proposto - podendo ser utilizadas em estratégias de ensino-aprendizagem em várias temáticas na sala de aula.

Dessa forma, temos como hipótese que conceber as charges como artefatos culturais que fazem parte do processo de produção, circulação e textualização do conhecimento científico e tecnológico de um ponto de vista cultural pode propiciar subsídios para aprimorar o uso desses textos e da leitura no Ensino de Física. Possibilitando estabelecer conexões entre contextos histórico-culturais passados e contextos contemporâneos.

A perspectiva deste artigo corrobora com Moura e Guerra (2016) em considerar fundamental a utilização do contexto histórico de produção das Ciências, assim como suas relações com outras produções culturais que compartilham o mesmo contexto. As charges, objeto de análise deste trabalho, fazem parte dessas "outras produções culturais". Artefatos que comunicam, circulam e textualizam noções de Ciências e tecnologias não independentemente do seu contexto e condicionantes histórico-culturais.

Sendo assim, este artigo não se limita a analisar separadamente o texto (charge) dos conhecimentos e práticas relacionados aos episódios históricos, mas a sua textualização, segundo Silva (2019, p. 9), "[...] uma abordagem que analise essa simultaneidade ali presente, a da forma do texto e a do conhecimento que ele veicula". Com isso, consideramos as charges como textos e pensamos nas relações entre estes e "conhecimentos científicos para além de um viés puramente conteudista" (SILVA, 2019, p. 12). Ao adotarmos a noção de textualização pressupomos esta relação constitutiva, em que as especificidades da linguagem e de seu contexto histórico e cultural de produção precisam ser consideradas (SILVA, 2019). As charges, nosso objeto de análise, são textos, artefatos culturais, com inúmeras especificidades e elementos que se articulam, inclusive com possibilidade de sobreposição imagética e verbal. 


\section{Os eclipses, as charges e seus meandros...}

Ao considerar uma curvatura do espaço, as medidas de deflexão da luz de estrelas durante um eclipse total do sol constituíram-se num evento ímpar na Ciência e para sua própria História, pois tais medidas proporcionaram a primeira corroboração empírica de uma das bases da TRG. Sendo que

As medidas da deflexão da luz das estrelas na borda do Sol constituíram uma evidência muito forte para a confirmação e a aceitação da teoria da relatividade geral de Einstein. Essa teoria alterou profundamente a nossa visão sobre o universo. Ela suplantou a teoria gravitacional que Newton havia formulado cerca de dois séculos antes e foi um acontecimento de extraordinária importância na ciência (MOREIRA, 2019a, p. 32).

Antes de publicar as considerações finais sobre TRG, Einstein tinha deduzido, em 1911, um valor do ângulo de deflexão da luz (0,875 segundos de arco) provenientes de estrelas ao passar nas vizinhanças do Sol, ao analisar a influência de um campo gravitacional intenso na propagação da luz (MOREIRA, 2019b).

Einstein fez isso sem conhecer os resultados anteriores e levando em conta seu Princípio da Equivalência. Logo em seguida, ele sugeriu a astrônomos que esse ângulo poderia ser medido em um eclipse total do Sol, por meio de fotografias de estrelas cuja luz passasse na borda do Sol comparadas com fotos das mesmas estrelas quando o Sol não estivesse mais na frente delas" (MOREIRA, 2019b, p. 13).

Para que a deflexão da luz por um campo gravitacional intenso fosse registrada e posteriormente calculada era necessário fazer fotografias das luzes das estrelas "próximas" do Sol em uma situação de eclipse total do Sol, pois em nenhuma outra situação em ambiente terrestre o fenômeno é possível de ser registrado devido a uma fraca ou forte intensidade luminosa (MOURÃO, 1993). Assim, justificou-se a necessidade de observar e registar eclipses totais do Sol.

Tentativas de medir a deflexão da luz de estrelas aconteceram já em 1912, por uma expedição astronômica argentina dirigida por Charles Perrine. "Perrine havia sido estimulado a fazê-lo por Erwin Finlay-Freundlich (1885-1964), astrônomo do Observatório de Berlim e amigo de Einstein. As observações, durante um eclipse total do Sol, seriam feitas no Brasil, na cidade Cristina (MG); mas choveu todo o tempo e nada foi medido" (MOREIRA, 2019b, p. 14).

Outra tentativa ocorreu em 1914, em plena primeira guerra mundial, nas regiões da Crimeia. Por questões políticas e de guerra, os astrônomos que viajaram para 
observar o eclipse de 1914, foram presos e tiveram seus equipamentos confiscados pelo exército russo ao serem confundidos como espiões inimigos do império russo (MOURÃO, 1993).

Outras duas tentativas igualmente frustradas ocorreram na Venezuela, em 1916, e nos Estados Unidos, em 1918 (MOREIRA, 2019b). As considerações finais da TRG foram publicadas por Einstein no início de 1916, após as tentativas de observações dos eclipses totais do Sol ocorridas em Minas Gerais (1912) e na Criméia (1914).

Em 1915, Einstein chegou à sua Teoria da Relatividade Geral baseado na ideia de que a gravitação resulta da alteração da geometria do espaço-tempo pela presença da matéria. A partir dela, previu que a luz das estrelas, ao seguir a trajetória mais curta neste espaço-tempo curvo, sofreria uma deflexão nas vizinhanças do Sol por um valor que seria o dobro do previsto na Teoria newtoniana, ou seja o ângulo de deflexão deveria ser aproximadamente 1,74" (MOREIRA, 2019b, p. 16).

A partir de 1917 e ainda durante a primeira guerra mundial, astrônomos britânicos começaram os preparativos para observar o eclipse solar que aconteceria em 1919 e medir a deflexão da luz de estrelas ao passar nas vizinhanças do Sol (MOREIRA, 2019b), agora com o valor corrigido do ângulo de deflexão. "Para isso, organizaram duas expedições para regiões nas quais o eclipse seria total: uma, com Arthur Eddington e Edwin Cottingham, para a Ilha do Príncipe, e outra, com Charles Davidson e Andrew Crommelin, para Sobral" (MOREIRA, 2019a, p. 32).

Diante desses múltiplos cenários de eclipses totais do Sol, sinalizamos que os observados no Brasil, ou sua tentativa, são o foco de análise deste artigo, o de 1912 e 1919. E, considerarmos a charge um artefato produzido culturalmente, ou seja, um instrumento que associamos com o fazer científico, assim como laboratórios, as publicações e imagens científicas (GUERRA, 2019).

Para este artigo, selecionamos as charges publicadas na revista O Malho (19021954). Fundada em 1902 na cidade do Rio de Janeiro, capital da República, era uma revista semanal ilustrada de grande circulação, com publicações de charges caracterizadas pela sátira e humor. A revista teve longevidade, sendo publicada até 1954, e contou com os principais chargistas do país (TEIXEIRA, 2001; VISCARDI; SOARES, 2018). A opção pela revista $O$ Malho se deu também a partir do trabalho de Moreira (2019a), que cita a charge da figura 1, associado ao fato da revista ser uma das com maior repercussão durante a década de 1910 (TEIXEIRA, 2001; TENÓRIO, 2009). 
A partir disso, para encontrar outras charges relacionadas às tentativas de observação dos eclipses totais do Sol, efetuamos buscas na Biblioteca Nacional Digital. Utilizamos como filtros no mecanismo de busca: a revista O Malho, a palavra "eclipse", publicações de 1912 e 1919. Ao todo encontramos sete charges publicadas em 1912. Sendo quatro publicações anteriores à tentativa de observação do eclipse (10/10/1912) e três posteriores e nenhuma publicada no ano de 1919. E, a sequência que aqui apresentamos e analisamos obedece à ordem cronológica de publicação delas.

\section{Figura 1: Por um óculo.}

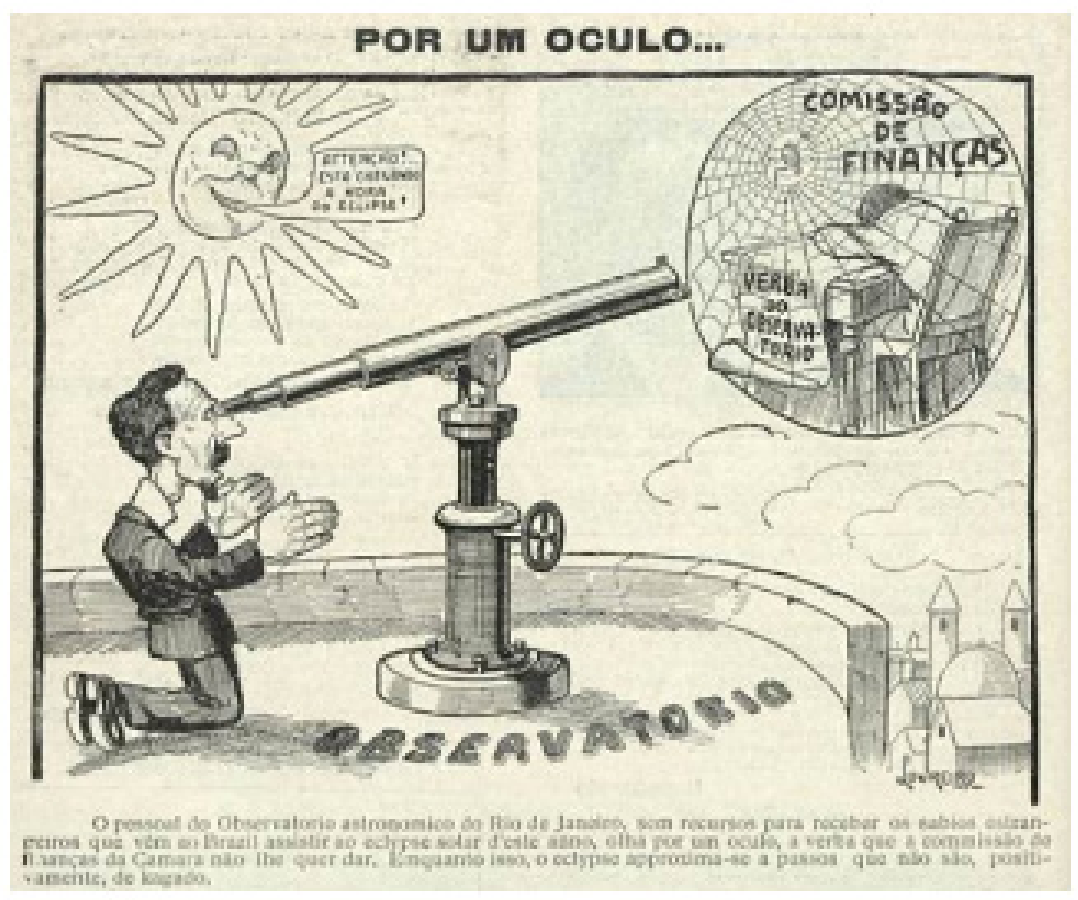

Fonte: O Malho, em 07 de setembro de 1912, N. 521.

A charge da Figura 1 é a primeira publicada pela revista $O$ Malho em 1912, aproximadamente um mês antes da tentativa de observação do eclipse.

A charge se refere ao contexto histórico do eclipse de 1912. Sua representação humorística teve como objetivo denunciar, criticar e satirizar um fato específico 
(MIANI, 2012) - a falta de recursos do Observatório Astronômico do Rio de Janeiro para receber astrônomos estrangeiros e viabilizar a observação do eclipse.

Aragão (2008) lembra que a charge é circunstancial. "O desconhecimento do contexto social no momento de publicação da charge pode levar a incompreensão da mesma" (ARAGÃO, 2008, p. 2979). No entanto, a crítica/sátira comunicada na charge de 1912 caberia ao contexto do eclipse de 1919 e atualmente com os cortes de verbas para pesquisas. A charge anterior rompe a limitação temporal apontada por Romualdo (2000).

Nas semanas que antecederam a chegada das comissões a Sobral, um assunto galvanizou jornais e revistas do Rio de Janeiro: o atraso na liberação dos recursos, já aprovados no orçamento do país, para a comissão brasileira se deslocar para Sobral e preparar a infraestrutura para a recepção das outras comissões (MOREIRA, 2019a, p. 35).

Entre os elementos imagéticos utilizados, temos a representação humana, caricaturada, de Henrique Morize - diretor do Observatório Nacional do Rio de Janeiro. Morize é retratado de joelhos e braços erguidos, observando com um óculo (luneta) alguém, de bruços sobre a mesa, na comissão de finanças. Eisner (2010, p. 106) salienta que, em quadrinhos, "a postura do corpo e o gesto têm primazia sobre $o$ texto. A maneira como são empregadas essas imagens modifica e define o significado que se pretende dar às palavras". A postura corporal de Morize, "ajoelhado e suplicante" que observa, segundo Moreira (2019a, p. 34) "a verba distante e coberta de teia de aranha na comissão de finanças, que tardava a sair". A postura suplicante de Morize, contradiz a postura corporal que remete à indiferença do personagem na "comissão de finanças", que parece dormir sobre a solicitação relacionada à "verba do observatório".

Ainda sobre quadrinhos em geral, Eisner (2010, p. 114) lembra que a aparência do rosto, familiar aos seres humanos, tem o papel de registrar emoções e "dá sentido à palavra escrita”. Nesta charge, o sol apresenta traços humanizados com um rosto que sorri. Sua expressão facial sugere um sorriso sarcástico, que anuncia que o eclipse está chegando, e o tempo de Morize terminando. A charge é potente também para abordar os meandros do eclipse de 1919.

De fato, a burocracia brasileira quase impediu as observações do eclipse de Sobral! Como reporta jocosamente O Malho (26/04/1919), o presidente do Tribunal de Contas teria sugerido a Morize, diante de mais uma solicitação desesperada para a liberação dos recursos: "Adie-se o eclipse" (MOREIRA, 2019a, p. 35). 
Frente à "lentidão burocrática [...] foi a empresa estatal Lloyd Brasileiro que, afinal, emprestou o dinheiro para a expedição da comissão brasileira [...]" (MOREIRA, 2019a, p. 35). Outros signos que trazem significado e que são percebidos pela ampliação do "óculo" é a aranha e sua teia. As teias de aranha "denotam itens com os quais somos mais ou menos familiarizados no nosso mundo real" (POSTEMA, 2018, p. 33). Este símbolo icônico agrega significado, pois além de representarem armadilhas para capturar presas, estão associadas a ambientes abandonados.

A charge da Figura 2, publicada apenas 20 dias antes do eclipse de 1912, ainda retrata a falta de recursos financeiros para viabilizar a observação do eclipse e receber as equipes de astrônomos estrangeiros.

Figura 2: Muito Mal...

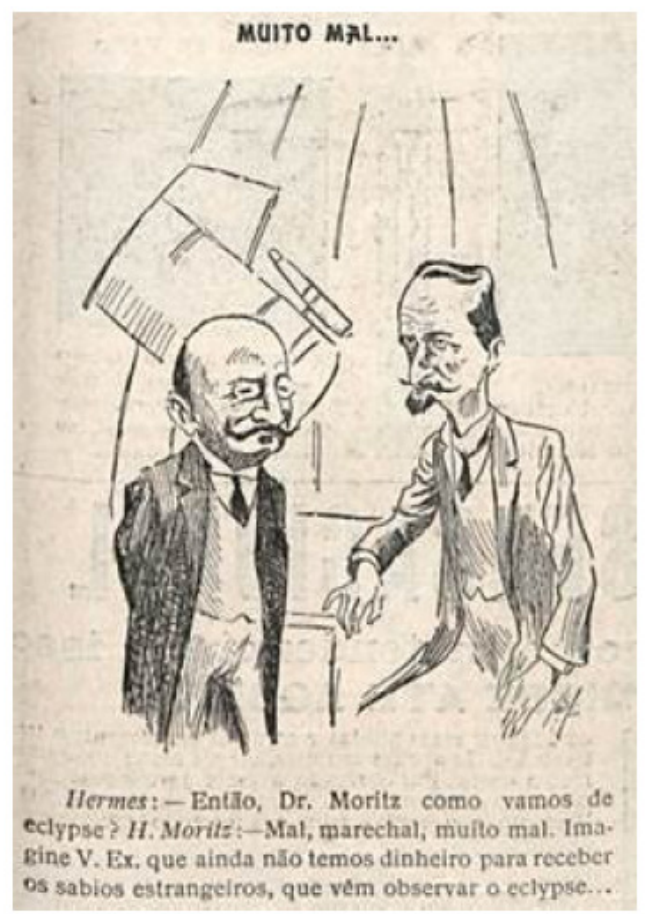

Fonte: O Malho, em 21 de setembro de 1912, N. 523.

Novamente Henrique Morize (à direita) é retratado agora, com o então presidente da república (1910-1914), marechal Hermes da Fonseca (à esquerda), que acompanhou a tentativa de observação do eclipse em Passa Quatro (MG) (MOREIRA, 2019a). 
Enquanto as duas charges anteriores abordaram a falta de recursos para receber a equipe de astrônomos estrangeiros, a charge da Figura 3, publicada cinco dias antes do eclipse de 1912, ilustra astrônomos observando o eclipse total do Sol e descreve em sua legenda sobre as elevadas despesas por parte dos governos, sendo que existiu atrasos para a aprovação e liberação dos recursos por parte do governo brasileiro (BARBOZA, 2012).

Figura 3: 0 eclipse total de 10 do corrente.

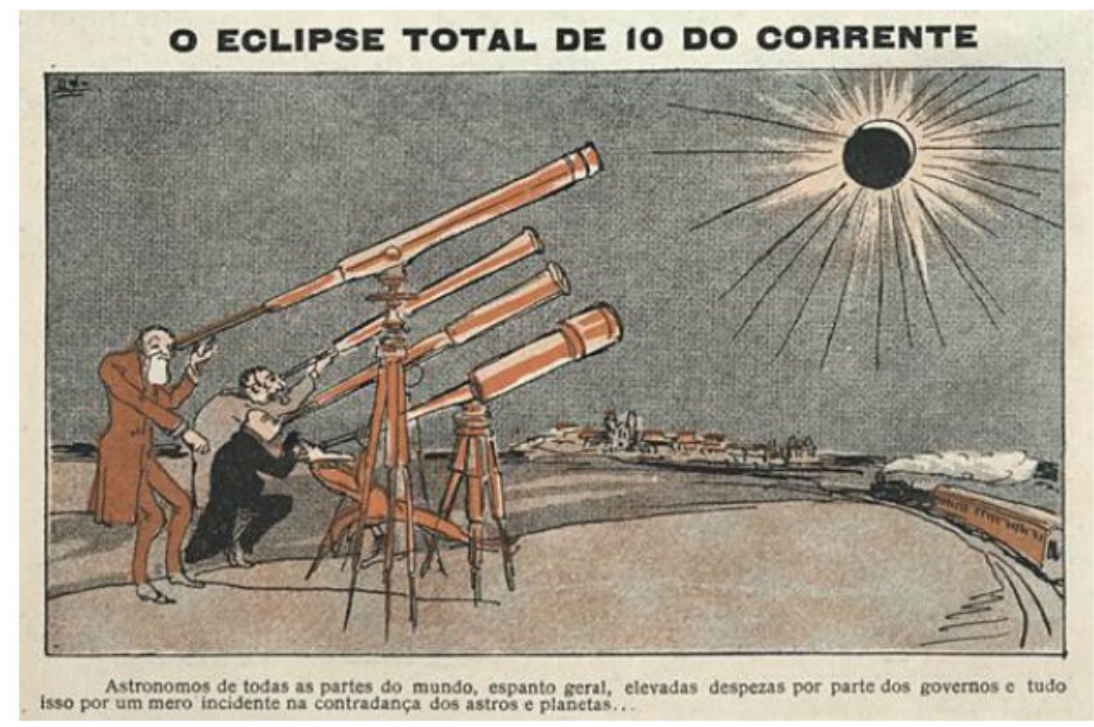

Fonte: O Malho, em 05 de outubro de 1912, N. 525.

Como ilustrado na Figura 3, o eclipse de 1912 atraiu astrônomos de diferentes partes do mundo. Oliveira (2010) destaca que: "Das oito expedições que foram observar o eclipse de 1912 no Brasil, seis eram de outros países (duas inglesas, uma francesa, duas argentinas e uma chilena)" (OLIVEIRA, 2010, p. 2). As expedições "foram enviadas para as cidades de Passa Quatro, Alfenas e Cristina no estado de Minas Gerais e Cruzeiro (SP) [...]" (ibidem) e tinham objetivos de pesquisas diferentes ao observar o eclipse.

As expedições inglesas, incluindo a composta pelos renomados astrônomos Arthur Eddington (do Observatório Real de Greenwich e chefe da expedição) e Charles Davidson, ficaram em Passa Quatro (MG). A expedição chefiada por Eddington ti- 
nha como objetivo "estudar a estrutura da coroa solar e verificar a presença de um elemento chamado coronium" (OLIVEIRA, 2010, p. 03). A outra expedição inglesa era do astrônomo amador James Henry Worthington, conhecido como "caçador de eclipse" - um homem rico que investigou assuntos científicos e tinha interesse especial em eclipses (CRISPINO, 2020). A expedição francesa também se instalou em Passa Quatro (MG) e tinha como objetivo realizar estudos da região verde do espectro solar (OLIVEIRA, 2010). Por fim, ficou em Passa Quatro (MG) a comissão brasileira, chefiada por Morize, e tinha como objetivo "realizar estudos sobre o magnetismo e a física do globo e fotografar a coroa solar" (OLIVEIRA, 2010, p. 4).

$\mathrm{Na}$ cidade de Cristina (MG) ficaram as comissões argentina e chilena. A expedição argentina, dirigida por Charles Perrine, tentou medir a deflexão da luz de estrelas (MOREIRA, 2019b). Outra expedição argentina, do Observatório Nacional de La Plata, se estabeleceu em Alfenas (MG) (CRISPINO, 2020). A outra comitiva brasileira, do Observatório de São Paulo, enviou uma expedição para a cidade de Cruzeiro (SP) (CRISPINO, 2020). Ficaram em Passa Quatro (MG), portanto, quatro expedições: as duas expedições inglesas, uma brasileira e outra francesa. A concentração das expedições em Passa Quatro não foi ao acaso.

Arthur Eddington estava em dúvida entre as cidades de Cristina (MG) e Cruzeiro (SP). "Além de estarem ambas próximas à linha central da totalidade, elas apresentavam outras características favoráveis para receber as expedições, tais como a altitude beirando os mil metros ('uma vantagem bastante incomum'), e a proximidade a uma estrada de ferro" (EDDINGTON, 1912 apud BARBOZA, 2010, p. 283). Estas condições tão favoráveis às duas cidades fizeram com que Eddington afirmasse: "Teme-se que praticamente todas as inúmeras expedições enviadas para observar o eclipse irão provavelmente escolher a mesma localidade; isto não é nada desejável, mas é quase inevitável quando um local parece muito mais vantajoso que qualquer outro" (EDDINGTON, 1912 apud BARBOZA, 2010, p. 283).

Mas a previsão de chuva e a possibilidade de atrasos para transportar os pesados equipamentos em virtude de se afastarem da estrada de ferro fizeram com que as expedições inglesas optassem, também, por Passa Quatro (MG) - mesma cidade escolhida pela expedição francesa e brasileira (BARBOZA, 2010).

A charge da figura 3 não identifica a cidade em que a equipe de astrônomos realiza a observação, mas representa algo que foi fundamental para a realização desta prática científica que ocorreu em locais tão peculiares - o trem (canto inferior direito). 
Em Passa Quatro, as quatro expedições ficaram na fazenda Bella Vista, de propriedade de Rodolpho Hess. Uma fazenda próxima à ferrovia e distante aproximadamente de $1 \mathrm{~km}$ da cidade (CRISPINO, 2020). A escolha do local de observação, além de atender critérios geográficos onde o eclipse solar seria visível em sua totalidade, precisava atender outro critério: ser próximo à ferrovia. Algo fundamental para viabilizar o transporte dos equipamentos utilizados pelas diferentes comitivas.

As expedições inglesas deixaram o Rio de Janeiro em 21 de setembro de 1912, data em que Morize ainda aguardava a liberação de recursos (Figura 2), e pegaram o trem de São Paulo para a Cruzeiro (SP) (CRISPINO, 2020). "Seus instrumentos foram enviados em um trem anterior. Em Cruzeiro, os instrumentos tiveram que ser transferidos para uma linha de bitola estreita, ao longo da qual foram conduzidos, por uma pista de 20 milhas, até Passa Quatro, onde chegaram após uma viagem de 3 horas" (CRISPINO, 2020, p. 6, tradução nossa).

Depois de chegarem em Passa Quatro, no dia 22 de setembro, os equipamentos ainda tinham que ser transportados até a fazenda Bella Vista, local onde seriam montados.

Havia um transporte diário (locomotiva) da cidade de Passa Quatro, onde os cientistas estavam hospedados, até a fazenda dos Hess (distância de cerca de $1 \mathrm{~km}$ ), onde os instrumentos eram posicionados, saindo da cidade às $8 \mathrm{~h}$ e voltando às $11 \mathrm{~h}$, para o almoço, retornando às $13 \mathrm{~h}$ e voltando às $18 \mathrm{~h}$ (CRISPINO, 2020, pp. 06-08, destaque e tradução nossa).

A expedição argentina chegou ao Rio de Janeiro de navio e trouxeram quase duas toneladas de equipamentos (CRISPINO, 2020). Do Rio de Janeiro até Cristina (MG), cidade em que a comitiva se instalou, são aproximadamente $350 \mathrm{~km}$.

O Observatório Nacional do Brasil se encarregou do transporte dos instrumentos da equipe Córdoba do Rio a Cristina, que chegaram ao destino no dia 24 de setembro. O local escolhido por Perrine em Cristina (...) para instalar o seu equipamento, foi aos arredores de um edifício (que, até então, nunca tinha sido utilizado após a sua construção) situado a cerca de 100 m da estação ferroviária (CRISPINO, 2020, p. 8, destaque e tradução nossa).

A escolha dos locais de observação próximos às estradas de ferro foram condicionantes e determinantes, já que dezenas de toneladas de equipamentos foram transportados pelas ferrovias do Brasil em 1912 (CRISPINO, 2020). Transportes custeados pelo governo federal brasileiro, como salienta Hussey, chefe da expedição argentina que foi para Alfenas: (...) o Governo Federal pagou as despesas de ferro- 
via dos astrônomos visitantes e suas despesas de hotel enquanto eles estiveram na Capital" (HUSSEY, 1913, p. 95, tradução nossa). Custos que, associados a dispensa das taxas alfandegárias sobre os instrumentos transportados pelos astrônomos/ cientistas (CRISPINO, 2020), ecoaram na forma de crítica como representado na legenda da figura 3: "[...] elevadas despesas por parte dos governos [...]".

Outro aspecto que chama a atenção é a articulação do fenômeno eclipse total do Sol, amplamente divulgado na mídia (MOREIRA, 2019a), e um contexto explicitamente político - candidaturas presidenciais. Vide figuras 4 e 5.

De maneira geral, a charge tem a essência de ser uma representação artística que se refere a uma situação do âmbito político, social ou cultural, o que reforça nosso entendimento da charge como um importante elemento histórico.

As charges das figuras 4 e 5 exigem um público atualizado dos principais fatos políticos daquele contexto (ARAGÃO, 2008), assim como da ocorrência do próprio eclipse total do Sol, visível em boa parte do Brasil.

A charge da Figura 4, uma metáfora política, utiliza em seu texto verbal, em forma de legenda, expressões comuns para comunicar o fenômeno celeste que iria ocorrer: "Astronomia", "phenomenos", "systema" e "eclypsar". No entanto, ressignifica estas expressões politicamente: "Astronomia politica", "soes do sistema planetário da Republica" e "eclypsar os demais".

Figura 4: $O$ eclipse total de 10 do corrente.

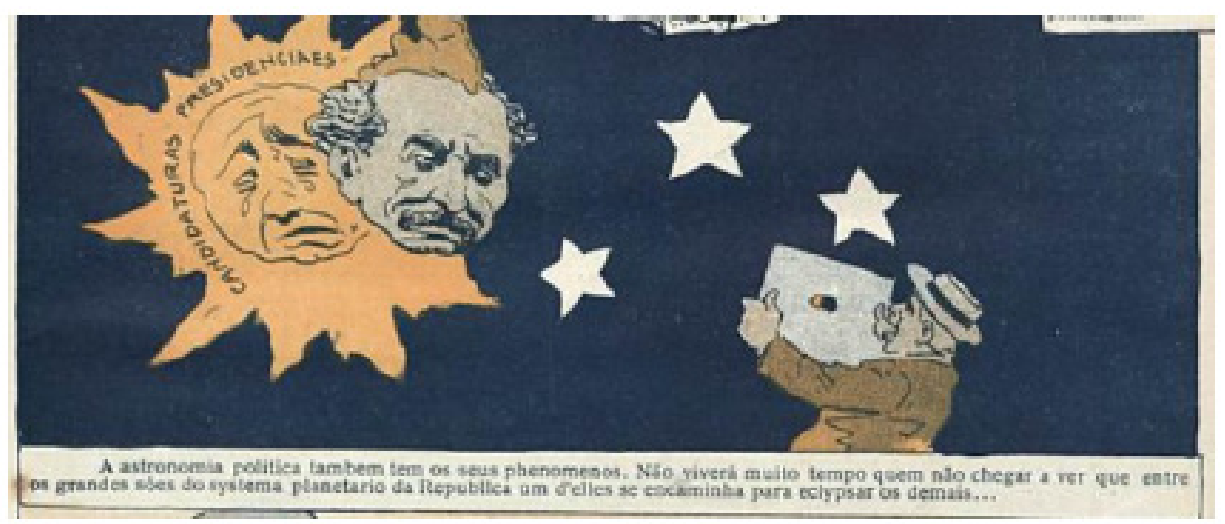

Fonte: O Malho, em 05 de outubro de 1912, N. 525. 
Figura 5: Capa da revista $O$ Malho.

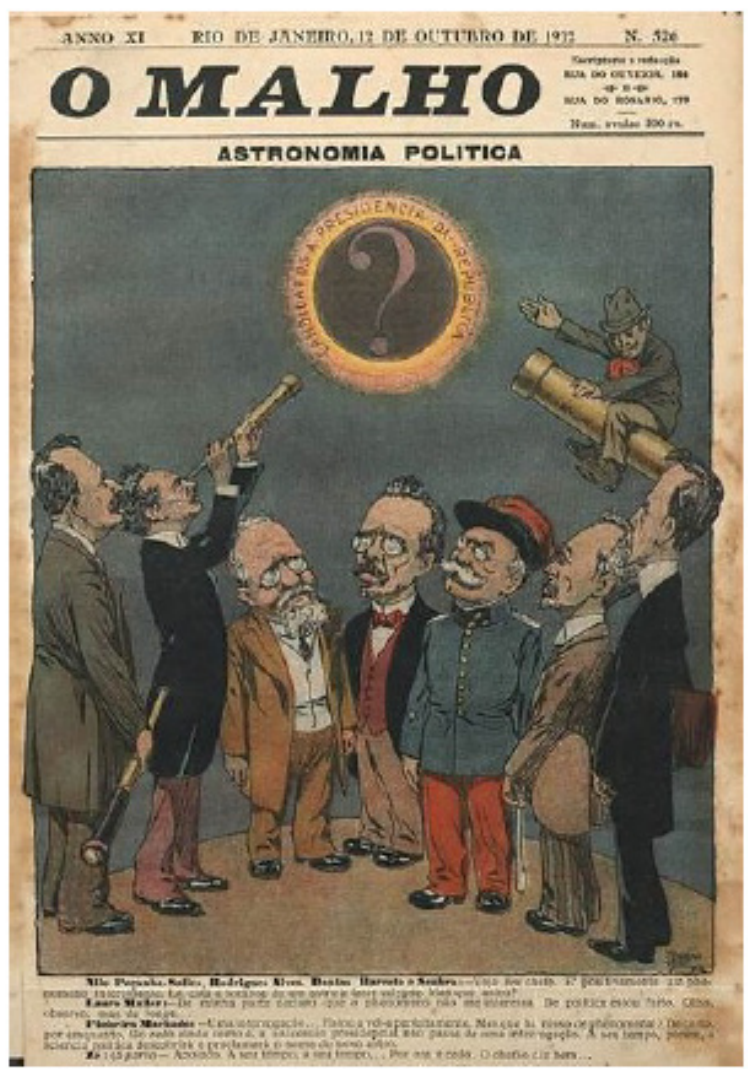

Fonte: O Malho, em 12 de outubro de 1912, N. 526.

Para potencializar a leitura da charge, que estabelece com as notícias daquele momento uma relação intertextual (ROMUALDO, 2000), o leitor precisaria conhecer estes acontecimentos, estas notícias. Importante lembrar que $O$ Malho era uma revista ilustrada, que além de charges, trazia desde assuntos corriqueiros aos acontecimentos nacionais mais relevantes (VISCARDI; SOARES, 2018).

Voltando a charges das figuras 4 e 5, quem eclipsa o Sol? Quem eclipsa os demais candidatos à presidência da república? O personagem ilustrado na figura 4 era figura comum em $O$ Malho e de grande destaque no cenário nacional naquele contexto: José Gomes Pinheiro Machado.

Pinheiro Machado, como citado na legenda da figura 5, foi um dos políticos mais influentes da República Velha (1889-1930). Apoiador da candidatura de Hermes da 
Fonseca em oposição a Rui Barbosa, em 1910, teve o ápice do seu poder, justamente no governo do Marechal Hermes (1910-1914). Era um nome forte para a sucessão presidencial pelo Partido Republicano Conservador.

$\mathrm{Na}$ charge da figura 5, que foi capa da revista dois dias depois do eclipse, além do Pinheiro Machado, outros possíveis candidatos à presidência da república são ilustrados: José Joaquim Seabra, Campos Salles, Nilo Peçanha, Dantas Barreto, Rodrigues Alves e Lauro Muller. Este último, acompanhou o eclipse em Passa Quatro ao lado do presidente (Hermes da Fonseca) e do vice-presidente (Venceslau Brás) (CRISPINO, 2020).

Nas duas metáforas políticas, articuladas ao eclipse total do Sol, há a presença de instrumentos utilizados durante a prática científica, como os telescópios (figura 5) e a necessidade de "vidros esfumaçados" (MOREIRA, 2019a) para observar o Sol (figura 4). Na figura 4, um detalhe que chama a atenção é a representação de estrelas durante o eclipse. Estrelas com suas luzes desviadas que só são observáveis durante o céu diurno nesta condição de Sol eclipsado, tão particular e tão perseguida por astrônomos em 1912 e 1919, no Brasil.

Na charge da figura 5, além dos políticos do cenário nacional, há a representação de outro personagem (Zé, na legenda) que valida a afirmação de Pinheiro Machado, se referindo a ele como "chefão". O personagem Zé Povo, presença constante nas charges de $O$ Malho, é visto por Tenório (2009) como "porta-voz da cidadania republicana" e também "das posições" da revista $O$ Malho.

Em 1910 a revista $O$ Malho mudou de dono. O novo proprietário era Antônio Francisco de Azeredo, jornalista e político - foi deputado e senador (por três décadas). Antônio Azeredo era "amigo do líder político gaúcho Pinheiro Machado, com quem fundou em 1910 o Partido Republicano Conservador (PRC). Tornou-se membro da comissão executiva do partido e uma de suas figuras mais importantes" (ABREU, 2015, p. 01).

Além de político, Antônio Azeredo atuou fortemente na imprensa. Sendo proprietário da revista $O$ Malho, entre 1910 e 1918, fundador e responsável pela redação da Gazeta da Tarde e do jornal Diário de Notícias. Foi, também, proprietário e redator chefe da A Tribuna (ABREU, 2015). "De modo geral, lançava mão de seu prestígio político, dos periódicos sob seu controle e das relações com o Poder Executivo federal para manter e ampliar sua base política no estado" (ABREU, 2015, p. 01). Nesta direção, Teixeira (2001, p. 39) aponta para 
o esvaziamento do conteúdo político e a conseqüente perda de agressividade da charge na República Velha - matérias-primas com que ela constrói sua linguagem e marca fundamental de sua futura modernidade - resultam agora num traço de exaltação e aliança com os políticos, às vezes francamente favorável, como nos governos de Rodrigues Alves e Afonso Pena, às vezes levemente satíricas, como nos de Campos Sales e Hermes da Fonseca (TEIXEIRA, 2001, p. 39).

Outro aspecto abordado nas charges se relaciona ao comportamento de animais durante o eclipse e as crendices populares - Figura 6. A mudança no comportamento animal em decorrência do ciclo claro-escuro é salientada por Portugal (2019):

De todos os eventos cósmicos, os eclipses solares provocam talvez a maior mudança no comportamento animal. Animais confusos que estão ativos durante o dia voltam para suas residências noturnas (...). Em todo o mundo, incidências incomuns de comportamento são geralmente relatadas enquanto todos os outros estão assistindo ao eclipse (PORTUGAL, 2019, tradução nossa e online).

Figura 6: A redor do eclipse.

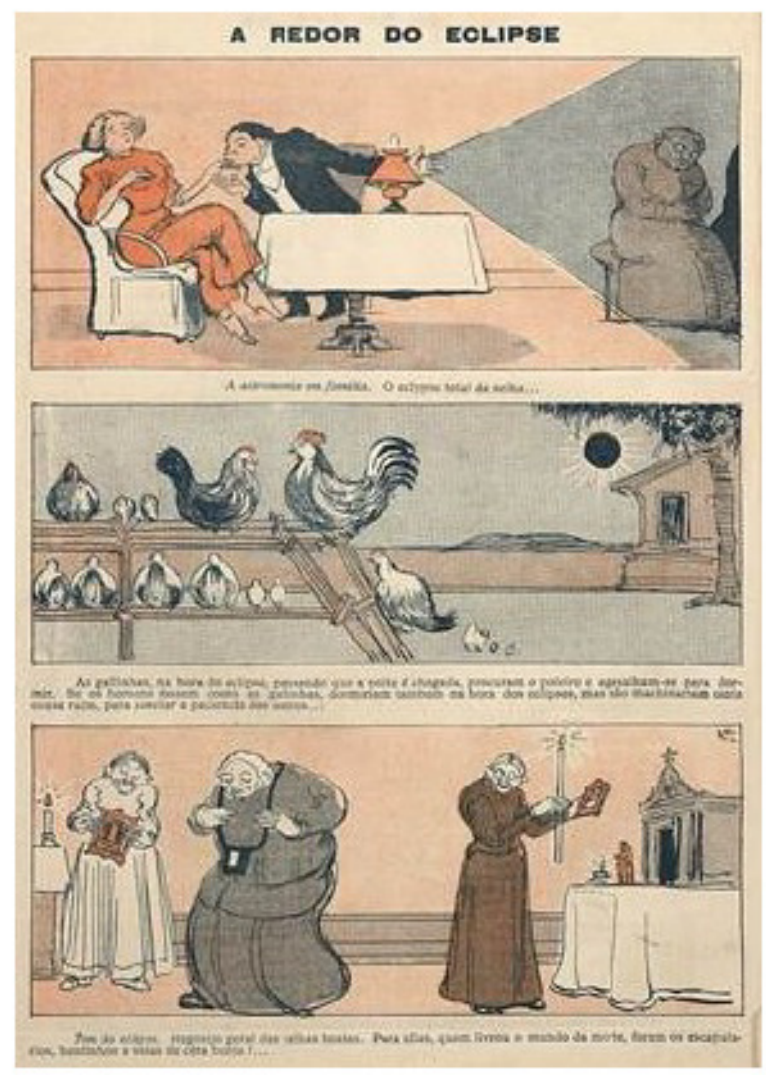

Fonte: O Malho, em 12 de outubro de 1912, N. 526. 
Incidência retratada na charge que ilustra o comportamento das galinhas durante o eclipse: "As galinhas, na hora do eclipse, pensando que a noite é chegada, procuram o poleiro e agasalham-se para dormir".

A alteração na luminosidade durante o eclipse foi salientada por Eddington, um dos astrônomos presentes: "O rápido aumento da escuridão algum segundo antes da totalidade foi muito impressionante, assim como o foi o brilho quase instantâneo quando acabou. Provavelmente o estado da atmosfera fez com que o eclipse fosse incomumente escuro" (CRISPINO, 2020, p. 21, tradução nossa).

A Figura 6 ilustra, ainda, o alívio das "beatas" após o final do eclipse. Nesta direção, Moreira (2019a) aponta que uma das matérias mais comuns da mídia sobre a cobertura dos eclipses foram os "textos que tratam de crendices e medos em relação ao eclipse” (MOREIRA, 2019a, p. 33).

Em 1919, alguns dias antes da observação do eclipse de Sobral, Morize publicou um artigo em A Tribuna explicando o eclipse como um fenômeno natural e "menciona os temores a ele associados pelos povos 'selvagens' e conclama a população a se manter em completa calma [...]” (MOREIRA, 2019a, p. 36, grifo do autor).

A última charge publicada pela revista $O$ Malho em 1912, nove dias depois do eclipse, é a da Figura 7.

Figura 7: $O$ que foi o eclipse.

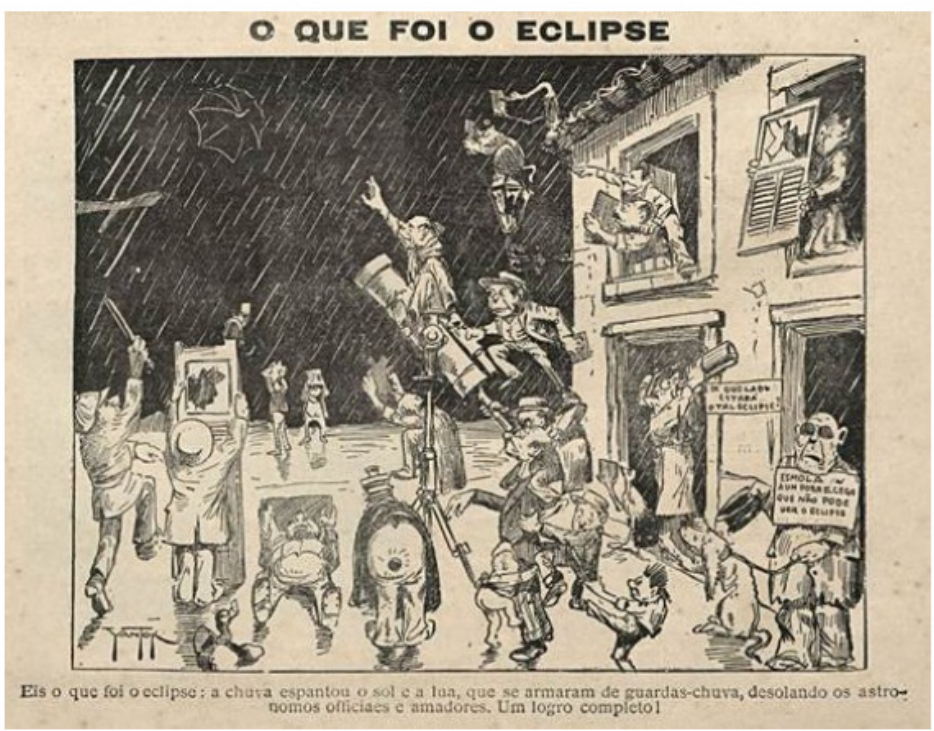

Fonte: O Malho, em 19 de outubro de 1912, N. 527. 
A charge ilustra alguns cuidados que repercutiram nos jornais para observar o eclipse, como "a necessidade do uso de vidros esfumaçados para se olhar o Sol" (MOREIRA, 2019a, p. 36). Um detalhe que chama a atenção é a utilização de janelas quebradas para observar o Sol, uma prática realizada pela população em situações de eclipse total do Sol, como ocorreu também em 1919.

Mas a charge evidencia, principalmente, como os jornais e revistas repercutiram a tentativa de observação do eclipse: "O fracasso molhado, retumbante e em toda a linha das observações do eclipse de 1912, em função das chuvas generalizadas persistentes no dia do eclipse [...]" (MOREIRA, 2019a, p. 35). E, por estas condições climáticas, a primeira tentativa de fotografar as luzes de estrelas "próximas" do Sol não foi realizada.

Infelizmente, nuvens pesadas cobriram o céu em Passa Quatro por alguns dias [...], incluindo toda a duração do eclipse. No dia do eclipse, os astrônomos estavam prontos, apesar da chuva, pois deveria haver esperança de que, pelo menos durante a totalidade, pudesse ser avistada a porção do céu com o Sol eclipsado, mesmo que através das nuvens. Infelizmente, não foi o que aconteceu em Passa Quatro, nem em qualquer outra estação de observação do Brasil (CRISPINO, 2020, p. 19, tradução nossa).

Mas será que, como diz a legenda da charge, a tentativa de observação do eclipse de 1912 "Foi um ogro completo!"? O chefe da expedição argentina organizada pelo Observatório Astronômico da La Plata salienta em seu relatório:

Não pudemos observar o eclipse, mas nossa viagem não foi totalmente inútil, pois tivemos a oportunidade de trocar ideias com os astrônomos das expedições argentinas, chilenas, francesas e inglesas. Além disso, adquirimos informações interessantes para futuros eclipses, especialmente o que ocorrerá em maio de 1919, cuja zona total cruzará o semi-árido Ceará, cuja falta de chuvas garante de antemão uma feliz observação (HUSSEY, 1914, p. 97-98, tradução nossa).

Embora a expedição de La Plata não estivesse envolvida em medidas da deflexão da luz, o relatório de Hussey evidencia a troca de informações entre os astrônomos e a busca por observar e registrar o "efeito Einstein" ainda seria tentado em outras situações futuras de eclipse total do Sol.

Moreira (2019a) lembra que nesta tentativa frustrada de medir a deflexão da luz de estrelas pela expedição argentina do Observatório Nacional Argentino, lideradas por Perrine, vieram Davidson e Eddington - astrônomos que desempenharam importante papel na observação do eclipse de 1919. Nas medidas da deflexão da luz 
de estrelas pelo campo gravitacional do Sol, realizadas em 1919 em Sobral (Brasil) e Ilha do Príncipe (África), Davidson e Eddington, que estiveram no Brasil em 1912, foram para Sobral e Ilha do Príncipe, respectivamente.

Em 1912, a expedição britânica que Davidson e Eddington faziam parte não tinha como objetivo medir a deflexão da luz, mas a cooperação com Perrine e Morize foram determinantes para 1919. Como Moreira (2019a), entendemos que "as relações e cooperações entre vários astrônomos que estiveram naquela região para observar o eclipse e que interagiram, como Eddington, Perrine, Morize e Davidson, foram importantes e ajudariam na preparação das observações bem-sucedidas do eclipse de Sobral, sete anos depois" (MOREIRA, 2019a, p. 35).

Crispino (2020) aponta o provável desconhecimento do efeito Einstein em 1912 por Davidson e Eddington. Já conhecido por Perrine, que objetivava verificar experimentalmente o desvio da trajetória da luz ao percorrer um espaço curvo já em 1912:

Vale ressaltar o fato de Davidson e Eddington conhecerem Perrine no Rio de Janeiro, em 1912. Na ocasião, um dos principais objetivos da expedição de Perrine era verificar o efeito de curvatura da luz de Einstein, durante a expedição de Greenwich visava essencialmente estudar as propriedades da coroa solar e, muito provavelmente, Eddington e Davidson não estavam cientes desse efeito de Einstein (CRISPINO, 2020 , p. 26, tradução nossa).

Na mesma direção, Moreira salienta: "Possivelmente foi na interação entre Perrine e Eddington (comprovada por carta deste para sua mãe), no Rio de Janeiro, antes do eclipse de 1912, que o astrônomo britânico teve conhecimento da previsão de Einstein sobre a possível deflexão do raio luminoso nas vizinhanças do Sol” (MOREIRA, 2019b, p. 18).

Em 29 de maio de 1919 ocorreram as observações astronômicas realizadas durante o eclipse total do Sol, na cidade de Sobral, no interior do Ceará, Brasil comumente chamado de Eclipse de Sobral. A partir do sucesso dessa expedição e das medidas realizadas em Sobral, Einstein passou a ter enorme repercussão mundial (VIDEIRA, 2005). O evento foi tão importante, que o próprio Einstein declarou para a imprensa quando esteve no Brasil em 1925 que: "O problema concebido pelo meu cérebro foi resolvido pelo céu luminoso do Brasil”. Albert Einstein, em entrevista a Assis Chateaubriand, no O Jornal, em 1925. 


\section{Implicações para o ensino de Física e algumas considerações}

A análise das charges na perspectiva da História Cultural da Ciência (HCC) articulada à noção de textualização, buscou evidenciar processos de representação de uma prática científica relacionadas às medidas da deflexão da luz em eclipses totais do Sol. Assim, procurou abordar lugares em que esta prática foi produzida, as redes feitas pelas pessoas e dar visibilidade a personagens que não são centrais (MOURA; GUERRA, 2016). Desta forma, para além do conhecimento conceitual, procuramos caminhar em direção a uma abordagem social, política (MOURA; GUERRA, 2016; MOURA, 2019) e também textual.

As tentativas de observação do eclipse do Sol, em 1912, no Brasil, destinadas a testar as previsões de Einstein por Perrine e seus colegas do Observatório Nacional de Córdoba é um episódio "ignorado em praticamente todos os livros e artigos relativos ao tema, inclusive em textos especializados na história da relatividade geral [...]" (MOREIRA, 2019b, p. 11). Moreira (2019b) aponta, ainda que

[...] em muitos livros e artigos sobre relatividade geral, cosmologia ou história da ciência, desde textos mais técnicos até os de divulgação científica, floresceu uma deturpação histórica que atribui com frequência o mérito único dessas medidas a Eddington, certamente o personagem de maior destaque no processo, mas não o único com importância (MOREIRA, 2019b, p. 10).

Neste sentido, a utilização das charges na perspectiva da HCC pode favorecer a visibilidade de ações produzidas por outros atores (MOURA, 2019), como Morize e Perrine, e possibilitar discussões no contexto do ensino de Física de práticas científicas não comumente abordadas, por não serem consideradas práticas de "sucesso".

No episódio do eclipse de 1919, Morize desempenhou um trabalho imprescindível na preparação e realização da observação que ocorreu em Sobral (MOREIRA, 2019; ABALADA; GUERRA, 2020). O reconhecimento do papel central de Morize se deu através de cartas e relatórios (ABALADA; GUERRA, 2020), mas não “[...] valoriza adequadamente o importante trabalho para o sucesso das expedições, que foi realizado pela comissão brasileira, chefiada por Henrique Morize" (MOREIRA, 2019b, p. 15).

Nesta direção, Abalada e Guerra (2020, p. 13) salientam que "[...] a forma como o discurso é feito mostra como, na realidade, os membros da equipe brasileira [...] 
não são reconhecidos como pertencentes a prática e detentores do conhecimento aqui construído".

Morize teve um papel central na observação do eclipse de 1919, para a realização desta prática científica (ABALADA; GUERRA, 2020). Como apontam Abalada e Guerra (2020, p. 03) “[...] as expedições precisavam ser organizadas para a prática acontecer, já que em nenhuma das ocasiões a faixa de totalidade atingiu as regiões nas quais os observatórios se localizavam”. Mas Morize foi fundamental, também, no eclipse de 1912 (CRISPINO, 2020). Outro personagem central é Perrine, comumente ocultado em detrimento a Eddington, como salienta Moreira (2019b, p. 10): “[...] a figura isolada de Eddington é quase sempre associada ao empreendimento coletivo e os outros participantes do processo são ocultados".

Moreira (2019b) se refere à importância do eclipse de Sobral em 1919 e de outros astrônomos que participaram da observação e questiona: "por que a importância de Sobral e de outros astrônomos nas observações do eclipse de 1919 é minimizada em relação à da Ilha do Príncipe e à de Eddington? Por que Sobral e os outros astrônomos ficam quase sempre eclipsados?" (MOREIRA, 2019b, p. 14).

Como Abalada e Guerra (2020), acreditamos que a ênfase da observação na Ilha do Príncipe e em Eddington decorrem de "[...] visões historiográficas eurocêntricas, que costumam colocar o continente como o único produtor de conhecimento, impondo uma posição periférica a outros países, como é o caso do Brasil" (ABALADA; GUERRA, 2020, p. 1).

Assim, procuramos dar um passo para a superação dessas abordagens, resgatando outros atores sociais envolvidos na construção do conhecimento e das redes de relações estabelecidas entre as pessoas em 1912, como a interação de Eddington, Perrine e Morize. Interações fundamentais para a preparação das observações em 1919, assim como o provável conhecimento da previsão de Einstein por Eddington a partir da interação com Perrine em 1912 no Brasil (MOREIRA, 2019b). Esta interação entre Perrine, Eddington e Morize permite destacar outras práticas científicas, que não se restringem a atividades experimentais (MOURA; GUERRA, 2011). Mody (2015) aponta que

Tanto quanto os cientistas praticam a leitura e a escrita, eles também falam e ouvem: em conferências, em salas de aula, perante potenciais financiadores, em clubes de jornalistas, para grupos cívicos, etc. Falar ajuda os cientistas a disseminar as suas ideias, claro, mas também a lançar, aperfeiçoar, e testá-las (MODY, 2015, p. 1028, tradução nossa). 
A busca por financiamento e falta de recursos, contexto explorado nas charges em 1912 e que se repetiu em 1919, pode potencializar conexões com questões da Ciência mais contemporâneas, como os cortes orçamentários de verbas para as pesquisas. Abordagens em situações de ensino em que "a consequência não é buscar no contemporâneo algo que se aprendeu sobre a ciência no passado, mas sim pôr em discussão o presente à luz do passado" (MOURA, 2019, p. 183).

Os lugares em que a Ciência é produzida e seus contextos, como nos eclipses de 1912 e 1919, são outros aspectos que podem ser explorados em situações de ensino e potencializados a partir da articulação das charges na perspectiva da HCC. A observação de eclipses total do Sol, uma prática experimental que depende de inúmeras condições, como as condições meteorológicas e locais propícios de observação, são comumente realizadas longe das grandes cidades e centros de pesquisa.

Barboza (2010) salienta que a visibilidade dos fenômenos astronômicos em grandes cidades pode ser prejudicada por condições como a poeira, fumaça e poluição luminosa. No entanto, como apontam Abalada e Guerra (2020), esta prática depende de condições como "mobilização política, transporte de pessoas e equipamentos, análise e organização prévia do local de observação, estudo de condições climáticas do local, contribuição de nativos da região, boa relação entre os países envolvidos, utilização de tradutores e muitas outras condições iniciais" (ABALADA; GUERRA, 2020, p. 3).

Assim, os fatores que foram decisivos para a escolha de Sobral, em 1919, e das cidades mineiras e paulista, em 1912, como a proximidades dos pontos de observação às ferrovias para o transporte dos equipamentos, podem ser explorados na construção de episódios históricos de ensino sobre aspectos da Teoria da Relatividade Geral (TRG).

O transporte dos equipamentos das diferentes expedições astronômicas, em 1912 e 1919, custeados pelo governo brasileiro, se entrelaça com outras práticas invisibilizadas em 1919, como a participação de pedreiros, carpinteiros e intérprete colocados à disposição dos ingleses (ABALADA; GUERRA, 2020). Os habitantes de Sobral foram responsáveis pela construção de estruturas "para proteger e sustentar os equipamentos" (ABALADA; GUERRA, 2020, p. 13). Personagens que se somam a Morize e Perrine para o sucesso da observação astronômica que corroborou empiricamente com uma das bases da TRG. 
Abordagens históricas a partir das charges, na perspectiva da HCC articulada com a noção de textualização, podem favorecer a superação disciplinar da produção das Ciências, já que além da dimensão conceitual, os contextos histórico-culturais e as especificidades das linguagens e dos textos envolvidos são consideradas (SILVA, 2019).

Nesta direção, procuramos articular especificidades da linguagem dos quadrinhos ao contexto histórico-cultural, por exemplo, na charge da Figura 1. Assim, pela noção de textualização, superamos um viés conteudista. A análise das charges, portanto, não deu ênfase apenas às noções científicas ou aos fatos históricos, mas às suas representações materializadas por e em objeto cultural de mediação entre ciência e público, um objeto ainda contemporâneo, como as charges, e que possui, além disso, características específicas enquanto texto que se tornam também conteúdos do ensino.

Como Silva (2019), acreditamos que a noção de textualização é "um caminho frutífero para construir análises e leituras de textos que remetem à ciência que possam gerar mediações pedagógicas mais coerentes com uma concepção cultural da escola, das ciências da natureza e da educação em ciências" (SILVA, 2019, p. 16). Mediações pedagógicas que podem favorecer o exercício de análise do texto charge pelos estudantes, dando visibilidade a outros elementos/contextos/personagens/ meandros e aos próprios textos, enquanto artefatos culturais, que podem ter sido "eclipsados".

O artefato cultural textual charge é uma das primeiras manifestações artísticas incorporadas nos meios de comunicação de massa e presentes nos dias de hoje em diferentes mídias e plataformas de circulação. Ao levarmos este texto para a sala de aula, na perspectiva da noção de textualização, podemos "analisar, identificar e descrever [suas] características, estruturas, regularidades" (SILVA, 2019, p. 09). Desta forma, a articulação da HCC com a noção de textualização, pode contribuir para mediações pedagógicas no ensino em, sobre e pelas Ciências, a partir do, sobre e pelo texto, contribuindo para o aprimoramento da leitura da ciência enquanto prática cultural.

Ao tomarmos as charges como objetos de estudo, a partir da noção de textuali$z a c ̧ \tilde{o} o$, no âmbito da perspectiva da HCC, procuramos realizar um "exercício com potência deslocadora, política, epistemológica, educacional e culturalmente. Uma 
potência com implicações para reposicionamentos pelos sujeitos leitores e para mediações de suas leituras" (SILVA, 2019, p. 29).

Por fim, não encontramos charges na revista $O$ Malho sobre o episódio do eclipse de 1919. Mas, acreditamos que os elementos aqui apresentados evidenciam potencialidades da utilização de charges no ensino de Física numa perspectiva por meio da HCC articulada à textualização, onde a charge é divulgação e elemento constitutivo de uma prática científica. Acreditamos, ainda, que a análise pode sinalizar uma relação que por vezes não é tão simples, a saber: a relação do texto e seus meandros com a linguagem, suas práticas sociais, cultural e política de produção, com a dimensão conceitual, coletiva, histórica e epistemológica da produção da ciência.

\section{Agradecimentos}

Os autores agradecem ao apoio recebido do Instituto Federal de Santa Catarina (IFSC) e à Coordenação de Aperfeiçoamento de Pessoal de Nível Superior (CAPES).

\section{Cartoons and the cultural history of science: the eclipse and the light deflection}

\section{Abstract}

This paper aims to analyze historical and textual aspects in cartoons related to attempted observations of the deflection of light in eclipses that happened in Brazil in 1912 and 1919, based of the Cultural History of Science linked with the notion of textualization. Therefore, we didn't analyze the text (cartoon) apart from knowledge and practices related to the historical episodes. The analyzed cartoons were published in O Malho, an illustrated magazine with great circulation and repercussion in the 1910s. The selection of cartoons was made by searches in the Digital National Library. The analysis demonstrated representation processes of a commonly made unseen scientific practice, namely the attempted observations of the solar eclipse in 1912; it favored the visibility of actions from actors such as Henrique Morize and Charles Dillon Perrine; it highlighted scientific practices such as interactions between Perrine and Eddington, the search for funding and delays on getting financial resources and factors which were determining for choosing the observation points, e. g. their proximity to railroads. These elements substantiate the potentialities of using cartoons in Physics Teaching, in the perspective of the Cultural History of Science related to the notion of textualization, where the cartoon is both the publicizing and cultural element, constitutive of a scientific practice. The analysis indicates the relation between text/language with the conceptual, collective, historical, and epistemological dimensions of the production of science.

Keywords: Cultural History of Science; Textualization; Cartoons; Light deflection; Eclipse. 
ABALADA, Pedro; GUERRA, Andreia. Brasileiros e brasileiras e o eclipse de Sobral de 1919: um olhar a partir da História Cultural da Ciência. SEMINÁRIO NACIONAL DE HISTÓRIA DA CIÊNCIA E DA TECNOLOGIA, 17, Rio de Janeiro, 2020.

ABREU, Alzira Alves de. Dicionário histórico-biográfico da Primeira República (18891930). Editora FGV, 2015.

ARAGÃO, Verônica Palmira Salme. Charge e cartum: uma perspectiva semiolinguística do discurso. In: XI Simpósio Nacional de Letras e Linguística e I Simpósio Internacional de Letras e Linguística, Uberlândia. Múltiplas perspectivas em Linguística. Uberlândia: EDUFU, p. 2975-3007, 2008.

ASSIS, Lúcia Maria de; MARINHO, Elyssa Soares. História em quadrinhos: um gênero para sala de aula. In: NASCIMENTO, Luciana; ASSIS; Lúcia Maria de; OLIVEIRA, Aroldo Magno de (Org.). Linguagem e ensino do texto: teoria e prática. São Paulo: Blücher, 2016.

BARBOZA, Christina Helena da Motta. Ciência e natureza nas expedições astronômicas para o Brasil (1850-1920). Boletim do Museu Paraense Emílio Goeldi, Belém, v. 5, n. 2, p. 273-294, v. 5, p. 273-294, maio-ago. 2010.

BARBOZA, Christina Helena. Encontros e desencontros na observação do eclipse solar de 10 de outubro de 1912. SEMINÁRIO NACIONAL DE HISTÓRIA DA CIÊNCIA E DA TECNOLOGIA, $13,2012$.

BARROS, José D’Assunção. História Cultural - um panorama teórico e historiográfico. Textos de História, v. 11, n $\square$ 1-2, p. 145-171, dezembro, 2003.

BURKE, Peter. O que é história cultural? Editora Schwarcz-Companhia das Letras, 2008.

CAMEL, Tânia de Oliveira; MOURA, Cristiano Barbosa de; GUERRA, Andreia. Revolução Química e Historiografia: uma releitura a partir da História Cultural da Ciência para o Ensino de Química. Educación Química, v. 30, n. 1, p. 136-148, 2019.

CRISPINO, Luís Carlos Bassalo. The October 10, 1912 solar eclipse expeditions and the first attempt to measure light bending by the Sun. International Journal of Modern Physics D, v. 29 , n. 11 , p. $1-30,2020$.

EISNER, Will. Quadrinhos e arte sequencial. São Paulo: Martins Fontes, 2010.

FIORAVANTI, Carlos Henrique; ANDRADE, Rodrigo de Oliveira; MARQUES, Ivan da Costa. Os cientistas em quadrinhos: humanizando as ciências. História, Ciências, Saúde-Manguinhos, v. 23, n. 4, p. 1191-1208, 2016.

GUERRA, Andreia. Educação Científica numa abordagem histórico-cultural da ciência. In: SILVA, Ana Paula Bispo da; MOURA, Breno Arsioli (Org.). Objetivos humanísticos, conteúdos científicos: contribuições da história e da filosofia da Ciência para o ensino de Ciências. Campina Grande: EDUEPB, 2019.

GONÇALVES, Roberta Ferreira. As Aventuras d'O Tico-Tico: formação infantil no Brasil Republicano (1905-1962). 2019. Tese (Doutorado em História) - Universidade Federal Fluminense, 2019 
HUSSEY, William Joseph. El Eclipse del 10 de Octubre de 1912: La Expedición del Observatorio de La Plata. Publicaciones del Observatorio Astronómico de la Universidad Nacional de La Plata; Tomo 1. 1914.

JACQUES, Vinicius. Charge Metafórica em Sala de Aula: a Maçã de Newton e os Ombros de Gigantes. In: SILVA, Henrique César da (Org.). Ciências, Seus Textos e Linguagens: Ensaios sobre Circulação e Textualização de Conhecimentos Científicos e Matemáticos. 1a ed. Curitiba: CRV, 2019.

MIANI, Rozinaldo Antonio. Charge: uma prática discursiva e ideológica. 9a Arte, São Paulo, v. 1 , n. 1, p. 37-48, 2012.

MODY, Cyrus. C. M. Scientific Practice and Science Education. Science Education, v. 99, n. 6, p. 1026-1032, 2015.

MOREIRA, Ildeu de Castro. O eclipse solar de 1919, Einstein e a mídia brasileira. Ciência e Cultura, v. 71, n. 3, p. 32-38, 2019a.

MOREIRA, Ildeu de Castro. O eclipse de 1919: a comprovação da Teoria da Relatividade Geral, a física moderna e o Observatório Nacional. In: BOZI, Alba Lívia Tallon; PESSOA, Marília (org.); JONES, Awena; BAGANHA, Fernando; ADLINGTON, Jane (trad.). Rio de Janeiro: Observatório Nacional, 2019b.

MOURA, Cristiano Barbosa de; GUERRA, Andreia; AMARAL, Priscila do; OLIVEIRA, Fabiano. Entre o histórico e o contemporâneo: abordando as práticas científicas em um curso sobre história e filosofia das ciências. Enseñanza de las ciencias, n. Extra, p. 3517-3524, 2017.

MOURA, Cristiano Barbosa de. Educação Científica, História Cultural da Ciência e Currículo: Articulações Possíveis. 2019. Tese (Doutorado em Ciência, Tecnologia e Educação) Centro Federal de Educação Tecnológica Celso Suckow da Fonseca, 2019.

MOURA, Cristiano Barbosa de; GUERRA, Andreia. História Cultural da Ciência: Um Caminho Possível para a Discussão sobre as Práticas Científicas no Ensino de Ciências? Revista Brasileira de Pesquisa em Educação em Ciências, v. 16, n. 3, p. 725-748, 2016.

MOURÃO, Ronaldo Rogério de Freitas. Os eclipses da superstição a previsão matemática. Ed. Unisinos, 1993.

OLIVEIRA, Raquel dos Santos. O eclipse de 1912 e a correspondência entre os astrônomos Morize e Perrine. Anais do XIV Encontro Regional da ANPUH-RIO: Memória e Patrimônio. 2010.

PERON, Thiago da Silva; GUERRA, Andreia. A História Cultural da Ciência, cinema e o ensino das leis de Newton. Enseñanza de las ciencias, n. Extra, p. 3809-3814, 2017.

PIMENTEL, Juan. ¿Qué es la historia cultural de la ciencia? Arbor, v. 186, n. 743, p. 417-424, 2010.

PORTUGAL, Steve. Lunar and solar eclipses make animals do strange things. The Conversation, United States, 03 de jul. de 2019.

POSTEMA, Bárbara. Estrutura narrativa nos quadrinhos: construindo sentido a partir de fragmentos. São Paulo: Editora Peirópolis, 2018.

RAMOS, Paulo Eduardo. A leitura dos quadrinhos. São Paulo: Editora Contexto, 2010.

ROMUALDO, Edson Carlos. Charge jornalística: intertextualidade e polifonia: um estudo de charges da Folha de S. Paulo. Maringá: Eduem, 2000. 
SANTOS, Maria Eduarda do Nascimento Vaz Moniz dos. Encruzilhadas de mudança no limiar do século XXI: coconstrução do saber científico e da cidadania via ensino CTS de ciências. In: Anais do Encontro Nacional de Pesquisa em Educação em Ciências, Valinhos, 1999.

SECORD, James A. Knowledge in transit. Isis, v. 95, n. 4, p. 654-672, 2004.

SILVA, Henrique César da. A noção de textualização do conhecimento científico: veredas pelos estudos da ciência, conexões pela educação em ciências. In: SILVA, Henrique César da (Org.). Ciências, Seus Textos e Linguagens: Ensaios sobre Circulação e Textualização de Conhecimentos Científicos e Matemáticos. 1a ed. Curitiba: CRV, 2019.

TEIXEIRA, Luiz Guilherme Sodré. O traço como texto: a história da charge no Rio de Janeiro de 1860 a 1930. Rio de Janeiro: Fundação Casa de Rui Barbosa, 2001.

TENÓRIO, Guilherme Mendes. Zé Povo cidadão: humor e política nas páginas de O Malho. Rio de Janeiro: UERJ, 2009. Dissertação, Universidade do Estado do Rio de Janeiro, Programa de Pós-Graduação em História, 2009.

VERGUEIRO, Waldomiro. Uso das HQs no ensino. In: RAMA, A.; VERGEIRO, W. Como usar as histórias em quadrinhos na sala de aula. 4a ed. São Paulo: Editora Contexto, 2018.

VIDEIRA, Antonio Augusto Passos. Einstein e o Eclipse de 1919. Física na Escola, v. 6, n. 1, p. 83-87, 2005.

VISCARDI, Cláudia Maria Ribeiro; SOARES, Lívia Freitas Pinto Silva. Votos, partidos e eleições na Primeira República: a dinâmica política a partir das charges de O Malho. Revista de História, São Paulo, n. 177, 2018. 